\title{
Measurements of the dynamics and coupling of the equatorial thermosphere and the $F$-region ionosphere in Peru
}

\author{
M. A. BIONDI \\ Physics and Astronomy, University of Pittsburgh, Fifth and Bigelow Sts, Pittsburgh, Pennsylvania 15260, \\ U.S.A.
}

J. W. Meriwether JR

University of Michigan, U.S.A.

B. FEJER

CASS-Utah State University, U.S.A.

and

R. WOODMAN

I.G.P., Peru

(Received for publication 20 May 1988)

\begin{abstract}
Simultaneous Fabry-Perot Interferometer (FPI) and Incoherent Scatter Radar (ISR) observations from Arequipa and Jicamarca, Peru, respectively, were obtained on 24 and 25 September 1986, during which there was substantial geomagnetic activity. Comparison of the neutral thermosphere's zonal velocity (measured by the FPI during twilight and night-time) and the $F$-region plasma's zonal drift (measured by the ISR throughout the day and night) indicate that at certain times, such as evening twilight, the two motions are not correlated, but that in the late night they are. The change from uncorrelated to correlated motion occurs as the ionospheric electron density decays, leading to a decreasing Pedersen conductivity which diminishes $E$-region shorting of the $F$-region dynamo, allowing the local thermospheric winds to control the $F$-region ionospheric drift.
\end{abstract}

\section{INTRODUCTION}

As part of the CEDAR (Coupling, Energetics and Dynamics of the Atmospheric Regions) program, coordinated measurements of the dynamical behavior of the upper atmosphere and the ionosphere at $\sim 300 \mathrm{~km}$ altitude above the magnetic equator were made in September 1986. These studies were carried out during the GISMOS (Global Ionosphere Study and Measurements Of Substorms) campaign using an optical Fabry-Perot interferometer and an incoherent scatter radar to determine the neutral and ionospheric dynamics, as well as the coupling between the media.

The observations of the neutral thermosphere and the $F$-region ionospheric plasma were made from Arequipa and Jicamarca, respectively, whose locations are indicated on the map in Fig. 1. The Fabry-Perot interferometer (FPI) at Arequipa measured the Doppler shift and width of the $630.0 \mathrm{~nm}$ twilight and nightglow emission from $\sim 300 \mathrm{~km}$ altitude to determine the neutral thermosphere's velocity vector and temperature. The incoherent scatter radar (ISR) at Jicamarca measured the Doppler shift and power spectrum of e-m radiation backscattered by the ionospheric electrons to determine height resolved plasma drift velocities from $\sim 200$ to $600 \mathrm{~km}$. The regions of the upper atmosphere under observation in the present studies are shown by ellipses labelled $\mathrm{N}$, S, E, W for the FPI and by circles adjacent to Jicamarca for the ISR.

\section{MEASUREMENT TECHNIQUES}

\subsection{Fabry-Perot Interferometer}

The Fabry-Perot interferometer, its companion tilting filter photometer (used to monitor the intensities of $630.0 \mathrm{~nm}$ emission, scattered light and interfering airglow radiation) and the automated control system have been described in a number of publications (SIPLER et al., 1983; MERIWETHER et al., 1983, 1986). The $100 \mathrm{~mm}$ aperture FPI employs refractive index 


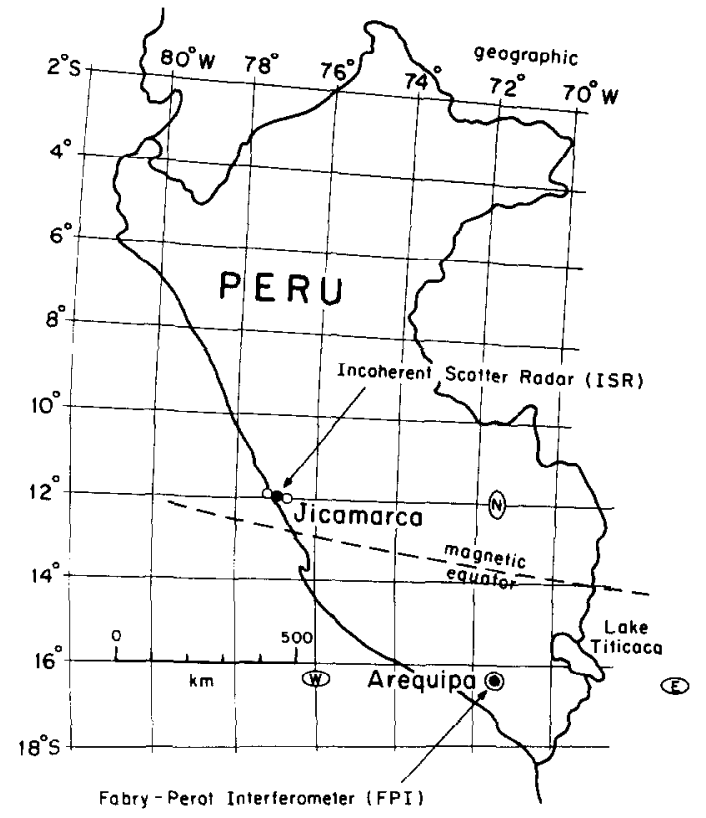

(s)

Fig. 1. Location of the equatorial optical and radar observatories at Arequipa and Jicamarca, Peru, respectively, and their fields of view at $300 \mathrm{~km}$ altitude (see text).

tuning, using argon gas which is compressed and expanded in the sealed system by means of a volume changer. $\mathrm{A} \sim 3.5$-fold increase in signal over a conventional center exit aperture instrument is obtained by use of a multiple aperture exit plate to field-widen the interferometer (BIONDI et al., 1985). Observations were typically made along the cardinal azimuths $\mathrm{N}$, $\mathrm{S}, \mathrm{E}, \mathrm{W}$ at $30^{\circ}$ elevation and vertically, leading to the fields of view (at $300 \mathrm{~km}$ altitude) indicated in Fig. 1.

Since the nightglow $630.0 \mathrm{~nm}$ emission at solar minimum was rather weak in the data shown here, the line profile scans were coherently summed for up to $20 \mathrm{~m}$ to obtain an adequate signal, leading to uncertainties in the velocity determinations ranging from $\sim 25$ to $60 \mathrm{~m} \mathrm{~s}^{-1}$. The Doppler shifts in the nightglow $630.0 \mathrm{~nm}$ line profiles were obtained by reference to the position in the FPI's interference order of the $632.8 \mathrm{~nm}$ line from a stabilized He-Ne laser, with the zero velocity reference provided by the vertical measurements on the assumption that vertical motions are usually small $\left(<10 \mathrm{~m} \mathrm{~s}^{-1}\right)$.

\subsection{Incoherent scatter radar}

The technique for measuring the $F$-region plasma drifts using the ISR at the Jicamarca Radar Observ- atory has been described by Woodman (1972). The radar beam was split in the direction perpendicular to the Earth's magnetic field into two beams approximately 3 to the $\mathrm{E}$ and $\mathrm{W}$ of vertical. The line-of-sight velocities determined from the Doppler shifts in the backscattered signal were then combined to obtain the vertical and zonal components of the ionosphere's drift. In the present data, the uncertainties in the night-time velocities were approximately $2-5 \mathrm{~m} \mathrm{~s}^{-1}$ and $20-50 \mathrm{~m} \mathrm{~s}^{-1}$ for vertical and zonal components, respectively, with the largest uncertainties in the latenight, low electron density period.

\section{RESULTS}

Simultaneous FPI and ISR observations were obtained on two days of the GISMOS campaign period, days 267 and 268, 24 and 25 September 1986, respectively. There was substantial geomagnetic activity during the period, as indicated by the $K p$ indices, which ranged between 2.5 and 4.5 on day 267 , and 2.5 and 5.5 on day 268 .

\subsection{FPI-determined thermospheric neutral winds}

The meridional and zonal components of the neutral wind vector for three days are shown in Fig. 2. The symbols on the graphs indicate the observing acimuths; the region of the thermosphere under observation in each case is indicated on the map in Fig. 1. The measurement uncertainties are indicated by the vertical lines through the symbols and, as noted earlier, ranged from $\pm 25 \mathrm{~m} \mathrm{~s}^{-1}$ at best, to more typical values of $\pm 50 \mathrm{~m} \mathrm{~s}^{-1}$ or somewhat larger.

Day 265 was geomagnetically quiet; the averages of the N,S meridional and $\mathrm{E}, \mathrm{W}$ zonal winds are small, $\sim 50 \mathrm{~m} \mathrm{~s}^{-1}$. Surprisingly, the zonal wind component appears to show a converging flow from 0200 0800 UT, which reaches a maximum at local midnight. Such quiet day behavior, while not at all well understood, has been observed at both equatorial and midlatitudes (BIONDI, 1984; BIONDI and SIPI.FR, 1985). However, in view of the very weak nightglow intensity on this quiet day, the deduced zonal velocities may be unrcliablc. For example, scattering from a dust or aerosol layer in the east could lead to a false determination (ABREU et al., 1983); however, the intensities to the $\mathrm{N}, \mathrm{S}, \mathrm{E}$ and $\mathrm{W}$ were all comparable, making this suggestion less tenable.

On the geomagnetically disturbed days 267 and 268 , larger wind velocities were observed, with a converging zonal flow on day 268 . On days 265 and 268 , when converging zonal flows were seen, the wind pattern observed to the west of Arequipa displayed 

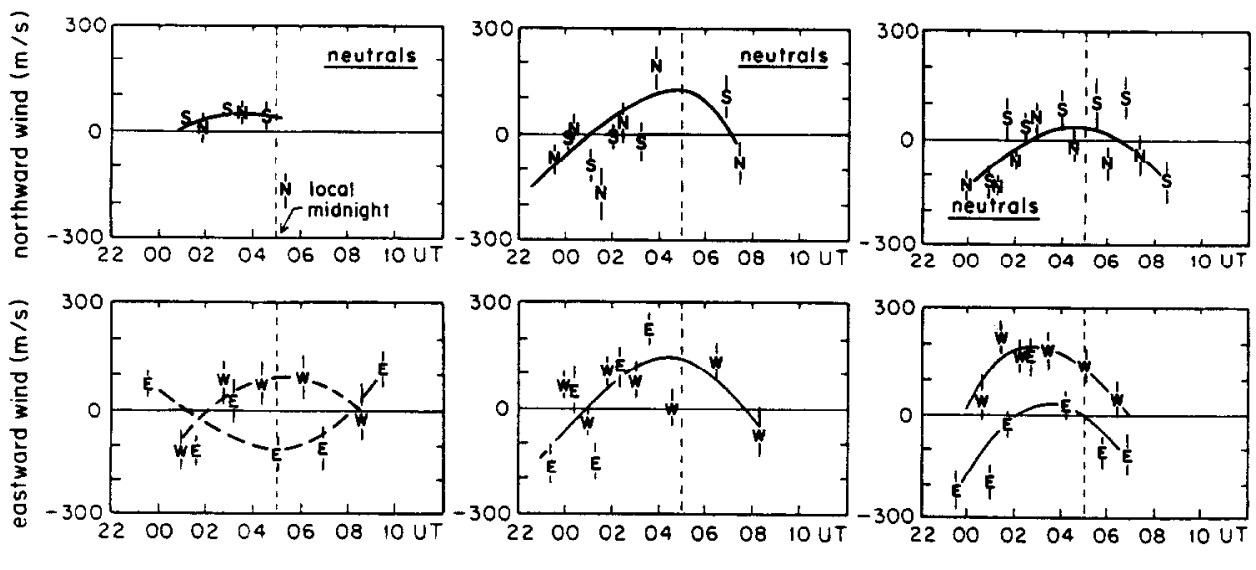

Doy 265,22 Sept. 1986

Doy 267,24 Sept. 1986

Day 268,25 Sept. 1986

Fig. 2. Measured meridional and zonal wind components in the neutral thermosphere at $\sim 300 \mathrm{~km}$ altitude above Arequipa, Peru on three nights in September 1986. The data symbols N,S,E, W refer to the cardinal direction observing azimuths. The uncertainties in the derived velocities range from \pm 25 to $\pm 50 \mathrm{~m} \mathrm{~s}^{-1}$.

the usual growth and decay of an eastward flow during the night (Meriwether et al., 1986), while the zonal velocity to the east exhibited unusual behavior.

\subsection{ISR-determined F-region plasma drifts}

The zonal and vertical components of the plasma drift were determined from 23 to 26 September 1986 (days 266-269). Figure 3 shows the height averaged drift velocity components near the $F$-region peak (at $\sim 300-400 \mathrm{~km}$ ) for the four day period. The sequences of small s symbols along the lower edges of the graphs indicate the occurrence of spread- $F$.

The zonal plasma drifts were westward during the day and mostly eastward at night, in agreement with previous radar measurements during solar minimum (cᄃ. FEJER et al., 1981, 1985). The east-west drift velocity does not seem to depend on geomagnetic activity. The vertical plasma drift can vary considerably with magnetic activity (as seen, for example, on 23 September) and from day-to-day (cf. FeJER, 1981, 1986). The large error bars on the late night data points for both components result from the very small electron densities at this time during solar minimum.

\subsection{Comparison of the FPI and ISR data}

The results of the FPI (neutral) and the ISR (plasma) zonal velocity measurements during the common observing periods are compared in Fig. 4. The post-sunset zonal motion of both the neutrals and the plasma became eastward and then died away after local midnight, perhaps reversing near dawn. The maximum eastward velocities attained by neutrals and plasma are comparable, especially if one uses values for the neutrals obtained by averaging the east and west looking observations on day 268 .

\section{DISCUSSION AND CONCLUSIONS}

Successful simultaneous measurements of the dynamics of both the neutral thermosphere and the $F$-region plasma were obtained on days 267 and 268 of 1986, in conjunction with the September 1986 GISMOS observation period. Although there was significant geomagnetic activity, the plasma's zonal (and vertical) drift shows a clear diurnal pattern; westward during the day and eastward at night. The neutrals exhibit a similar behavior at night (the only period of FPI measurements).

It will be seen from Fig. 4 that, before and shortly after sunset $(\sim 1800 \mathrm{LT})$, the zonal plasma drift was not controlled by the $F$-region neutral wind, and the plasma velocity was small. However, an hour or two after sunset the $F$-region plasma responded more to the thermospheric zonal wind, and the plasma drift increased. (It should be noted that the lack of coincidence, by $500 \mathrm{~km}$, in the upper atmosphere regions observed by the FPI and the ISR may also lead to differences in the observed motions. Perhaps the westward looking FPI observations, which are at almost the same magnetic longitude as that of the ISR observations, are to be preferred in the evaluation of the plasma-neutral coupled motion.)

These limited observations of correlated $F$-region plasma and neutral thermosphere motions in the late night are supported by the findings of HERRERo et al. (1985) and of HERrERo and MAYR (1986). They note 

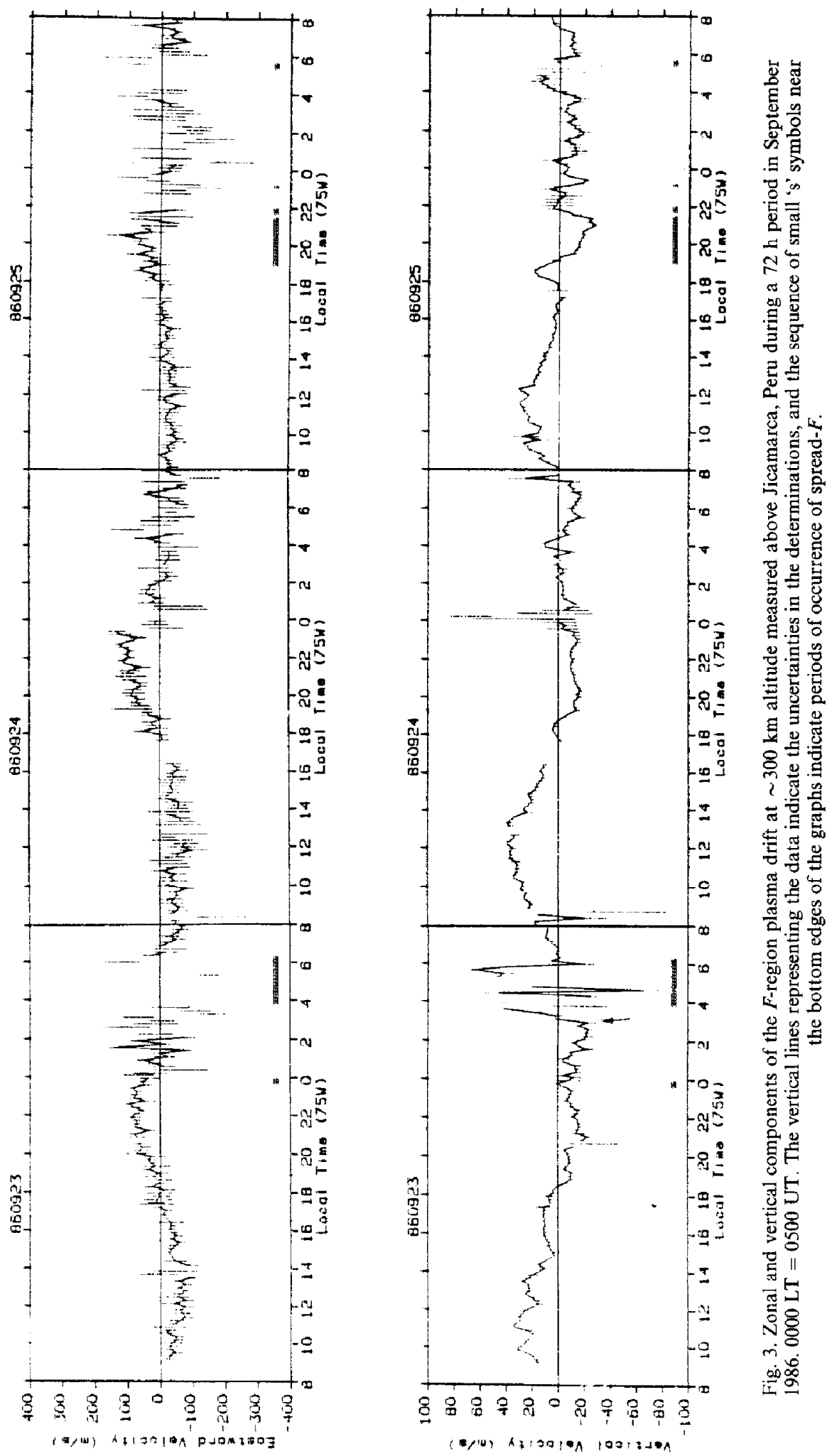

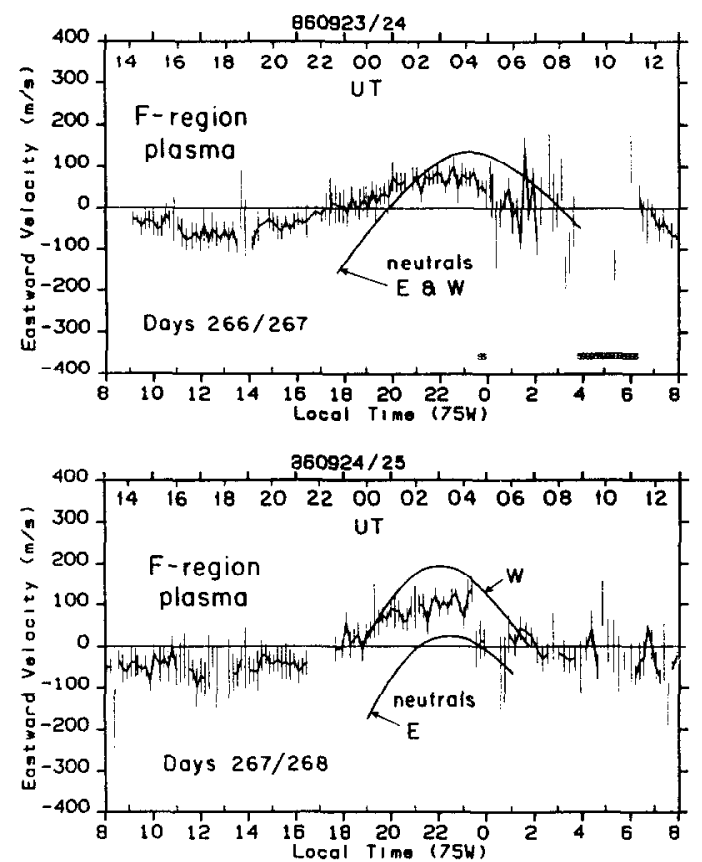

Fig. 4. Comprison of the zonal velocities of the neutral thermosphere and of the $F$-region ionospheric plasma during the periods of simultaneous observations. The smooth curves from Fig. 2 have been used to represent the neutrals' behavior.

a similar behavior in comparisons of diurnal variations of neutral winds (determined by DE-2) and plasma drifts (measured by the Jicamarca ISR) near solar maximum (1981-1982).

The change from uncorrelated to correlated motion of the two media can be understood on the basis of the following simple model (cf. RISHRFTH, 1971a): in the absence of the Earth's magnetic field (and electric fields) the zonal drift of the $F$-region plasma, through ion- and electron-neutral collisions ('ion drag'), would be the same as that of the neutral thermosphere. In the presence of the Earth's magnetic field, but with no coupling to other regions, e.g. the $E$-region, a near- vertical polarization (Hall) electric field would be set up as the zonal neutral wind tries to push the plasma across the near-horizontal north-south magnetic field lines. This $E$-field grows in strength until the resulting $\mathbf{E} \times \mathbf{B}$ zonal drift of the plasma matches the neutral thermosphere's velocity. However, when conductivity along the magnetic field lines is considered, this $E$ field may be reduced in value as a result of a shorting effect, which depends on the 'across B', height integrated Pedersen conductivity along the flux tube passing through the portion of the $F$-region under observation (RISHBETH, 1971b; WOODMAN, 1972).

In the present case, we invoke a reduction in the $F$ region's electric field by the shorting effect in the lower regions during the daytime and for a short time after sunset, accounting for the uncorrelated plasma and neutral zonal motions in the $F$-region at these times. Then, as the electron density of the $E$ - and $F$-regions decays in the post-sunset period, the shorting effect diminishes with the decreasing Pedersen conductivity, decoupling the $F$-region from the lower regions, so that the plasma now drifts with the neutral thermosphere. Unfortunately, we do not have height profiles for the electron densities in the equatorial regions during the observing periods from which to calculate the Pedersen conductivitics. We are thus unable, at present, to provide a quantitative test of our explanation of the observed $F$-region ionosphere and thermosphere behavior; however, the joint observation programs at Arequipa and Jicamarca are continuing with a view to obtaining the needed electron density profiles.

Acknowledgements-We thank the staff of the Jicamarca Radar Observatory for the radar measurements and W. SWARTZ and J. PINGREE of Cornell University for processing the radar data. This material is based upon work supported by the National Science Foundation, Division of Atmospheric Sciences, under Grants Nos. ATM-8502396 (University of Pittsburgh), ATM-8740490 (University of Michigan) and ATM-8616456 (Utah State University). Jicamarca Observatory is a facility of the Instituto Geofisico del Peru, Ministry of Education and is operated with support from the National Science Foundation.

\section{REFERENCES}

Abreu V. G., Schmitt G. A., Hays P. B., Meriwether J. W., Tepley C. A. and Cogger L. L.

BIONDI M. A.

Biondi M. A. and SiPLER D. P. Biondi M. A., Sipler D. P. and Weinschenker M. FEJer B. G.
Planet. Space Sci. 31, 303.
Geophys. Res. Lett. 11, 84.

Planet. Space Sci. 33, 817.

Appl. Opt. 24, 232.

J. atmos. terr. Phys. 43, 377 
FEJER B. G.

Fejer B. G., Farley D. T., Gonzales C. A., Woodman R. F. and Calderon C.

Fejer B. G., Kudeki E. and Farley D. T.

Herrero F. A. and MAYr H. G.

Herrero F. A., Mayr H. G., Spencer N. W., Hedin A. E. and FeJER B. G.

Meriwether J. W. JR, Tepley C. A., Price S. A. and HAYS $P$. B.

Meriwether J. W., MoOdY J. W., Biondi M. A. and ROBLE R. G.

RISHBETH H.

RISHBETH H.

Sipler D. P., Biondi M. A. and Roble R. G.

WOODMAN R. F.
1986 Solar Wind Magnetosphere Coupling (Kamide Y. and Slavin J. A. Eds), p. 519. Terra Scientific Publishing Co., Tokyo.

$1981 \quad J$.geophys. Res. 86, 215.

$1985 \quad J$. geophys. Res. 90, 12249.

1986 Geophys. Res. Lett. 13, 359.

1985 Geophys. Res. Lett. 8, 491.

1983 Opt. Engng 22, 128.

$1986 \quad J$. geophys. Res. 91, 5557.

1971a Planet. Space Sci. 19, 263.

1971b Planet. Space Sci. 19, 357.

1983 Planet. Space Sci. 31, 53.

1972 Space Res. 12, 969. 